UCRL-JC-121056

PREPRINT

CONF $-950905-6$

\title{
The Cryogenic Helium Cooling System for the Tokamak Physics Experiment
}

\section{RECEIVED}

NOV $1>1995$

OSTI

\author{
Brian Felker, Donald S. Slack and Craig R. Wendland
}

This paper was prepared for submittal to the Proceedings of the 16th IEEE/NPSS Symposium on Fusion Engineering

Champaign, Ilinois

September 30 - October 5, 1995

September 29, 1995

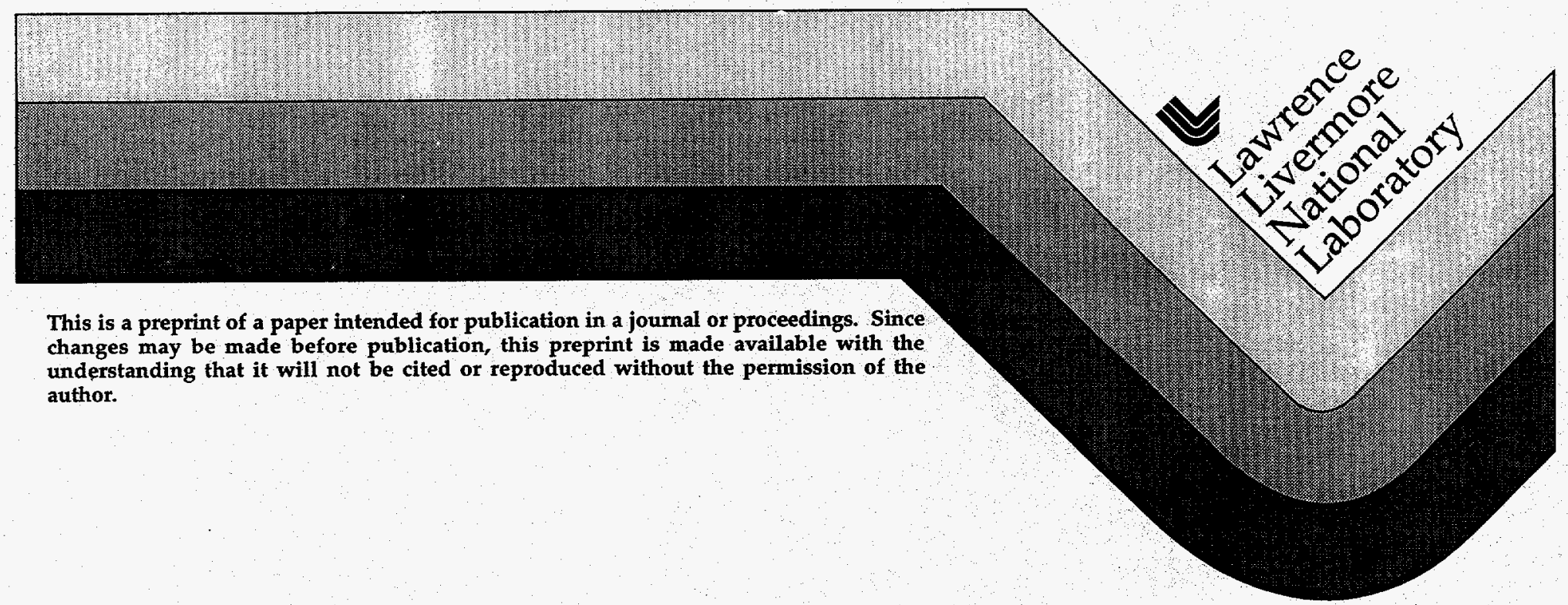




\section{DISCLAIMER}

This report was prepared as an account of work sponsored by an agency of the United States Government. Neither the United States Government nor any agency thereof, nor any of their employees, make any warranty, express or implied, or assumes any legal liability or responsibility for the accuracy, completeness, or usefulness of any information, apparatus, product, or process disclosed, or represents that its use would not infringe privately owned rights. Reference herein to any specific commercial product, process, or service by trade name, trademark, manufacturer, or otherwise does not necessarily constitute or imply its endorsement, recommendation, or favoring by the United States Government or any agency thereof. The views and opinions of authors expressed herein do not necessarily state or reflect those of the United States Government or any agency thereof. 


\section{DISCLAIMER}

Portions of this document may be illegible electronic image products. Images are produced from the best available original document. 


\title{
The Cryogenic Helium Cooling System for the Tokamak Physics Experiment
}

\author{
Brian Felker, Donald S. Slack and Craig R. Wendland \\ Lawrence Livermore National Laboratory \\ 7000 East Avenue, PO Box 808, L-643, Livermore CA 94550
}

\begin{abstract}
The Tokamak Physics Experiment (TPX) will use supercritical helium to cool all the magnets and supply helium to the Vacuum cryopumping subsystem. The heat loads will come from the standard steady state conduction and thermal radiation sources and from the pulsed loads of the nuclear and eddy currents caused by the Central Solenoid Coils and the plasma positioning coils. The operations of the TPX will begin with pulses of up to 1000 seconds in duration every 75 minutes. The helium system utilizes a pulse load leveling scheme to buffer out the effects of the pulse load and maintain a constant cryogenic plant operation.
\end{abstract}

The pulse load leveling scheme utilizes the thermal mass of liquid and gaseous helium stored in a remote dewar to absorb the pulses of the tokamak loads. The mass of the stored helium will buffer out the temperature pulses allowing $5 \mathrm{~K}$ helium to be delivered to the magnets throughout the length of the pulse. The temperature of the dewar will remain below $5 \mathrm{~K}$ with all the energy of the pulse absorbed.

This paper will present the details of the heat load sources, of the pulse load leveling scheme operations, a partial helium schematic, dewar temperature as a function of time, the heat load sources as a function of time and the helium temperature as a function of length along the various components that will be cooled.

\section{INTRODUCTION}

The Tokamak Physics Experiment (TPX) design uses NbTi and $\mathrm{Nb}_{3} \mathrm{Sn}$ Cable in Conduit Conductor (CICC) superconductor for all TF and PF coils. These CICC superconductors will be cooled to 5 Kelvin by supercritical helium. The cryogenic system, its circuits, loads, and future upgrade options are described in this paper.

\section{CRYOGENIC LOADS}

The critical points of all cryogenic systems are to provide the maximum cooling capacity to the various loads that must occur while minimizing the loads that will occur through radiation, conduction and gas conduction.

For the Cryogenics system of TPX, a current heat load table is produced every few months which summarizes numerous references published by the various participants in the Nation wide organization. The table is actually a compilation of several operating scenarios and analyses that are updated or newly accomplished during the intervening months.

The TPX document [1] partially presented here as Table $I$ is the latest heat load table that has been published. The loads of Table $\mathrm{I}$ are for the initial operations with $\mathrm{H}_{2}$ plasmas (No Nuclear) and for $D_{2}$ plasmas which are estimated to produce 5 e16 Neutrons/second.

Table I

\begin{tabular}{|c|c|c|}
\hline Pulsed Operations & No Nuclear & $\begin{array}{c}5.00 \text { e } 16 \\
\text { Neutrons per sec }\end{array}$ \\
\hline & $\begin{array}{l}10,1000 \mathrm{~s} \\
\text { pulses }\end{array}$ & $10,1000 \mathrm{~s}$ pulses \\
\hline Heat Load Item & $\begin{array}{l}\text { @ } 75 \mathrm{~min} \\
\text { intervals }\end{array}$ & $\begin{array}{l}@ 75 \mathrm{~min} \\
\text { intervals }\end{array}$ \\
\hline Duty cycle & $\begin{array}{c}\text { During ops } \\
24.1 \%\end{array}$ & $\begin{array}{r}\text { During ops } \\
24.1 \%\end{array}$ \\
\hline Steady State Loads & Watts & Watts \\
\hline $\begin{array}{l}\text { Thermal Radiation } \\
\text { From Vacuum Vessel } \\
\text { From Cryostat } \\
\text { From Bus Ducts } \\
\text { Conduction } \\
\text { From Bus Ducts } \\
\text { From Diag } \\
\text { From VCL Stacks } \\
\text { From Quench Vents } \\
\text { TF Supports } \\
\text { Total Piping losses } \\
\text { Cryo Valve losses } \\
\text { Bayonet losses } \\
\text { Mise } \\
\text { Other Steady State Loads } \\
\text { FECC Joints } \\
\text { All Magnet Joints }\end{array}$ & $\begin{array}{r}485 \\
110 \\
5 \\
620 \\
20 \\
0 \\
54 \\
35 \\
100 \\
210 \\
500 \\
20 \\
72 \\
260\end{array}$ & $\begin{array}{r}485 \\
110 \\
5 \\
620 \\
20 \\
0 \\
54 \\
35 \\
100 \\
210 \\
500 \\
20 \\
72 \\
260\end{array}$ \\
\hline Steady State Load Summary & 2491 & 2491 \\
\hline $\begin{array}{l}\text { Pulsed Loads } \\
\text { AC } \\
\text { PF1-7 } \\
\text { TF } \\
\text { Plasma Stabilization Coils } \\
\text { TF Case \& Structure } \\
\text { Nuclear } \\
\text { PF1 } \\
\text { PF2 } \\
\text { PF3 } \\
\text { PF4 } \\
\text { PF5 } \\
\text { PF6 } \\
\text { PF7 } \\
\text { TF } \\
\text { TF Case \& Structure } \\
\text { FECC }\end{array}$ & $\begin{array}{r}54 \\
26 \\
337 \\
9 \\
0 \\
9 \\
0\end{array}$ & $\begin{array}{r}54 \\
26 \\
337 \\
0 \\
0 \\
0 \\
6 \\
36 \\
109 \\
699 \\
1070\end{array}$ \\
\hline Pulsed Load Summary & 417 & 2337 \\
\hline $\begin{array}{l}\text { Cold Gas g/s Losses } \\
\text { Vapor Cooled Leads (VCL) } \\
\text { Ground Connection } \\
\text { Cryopump } \\
\text { Cold Gas Total g/s }\end{array}$ & $\begin{array}{r}26 \\
1.7 \\
32.7\end{array}$ & $\begin{array}{r}26 \\
1.7 \\
5 \\
32.7\end{array}$ \\
\hline Cold Gas Equiv Watts Summary & 3270 & 3270 \\
\hline Total Average Load & 6178 & 8098 \\
\hline
\end{tabular}




\section{ASSUMPTIONS AND LIMITATIONS}

The primary limitation on this original design of the TPX Cryogenic System is the MFTF-B $11 \mathrm{~kW}$ system. MFTF-B is a mothballed facility at LLNL. The cost savings of moving the system to PPPL for use on TPX are at least half the cost of a new system. Modifications to the MFTF-B system are designed into the move to make it more useful on TPX. Future upgrades beyond this initial move are designed to not have to modify any of the internal Tokamak plumbing. The Tokamak plumbing is designed to handle the full flows of all anticipated upgrades from the initial design forward.

Some of the Original MFTF-B Cryogenic System statistics are listed in Table II. The system was designed for production of liquid helium at atmospheric pressure. For TPX the system will be modified to cool the magnets with supercritical helium at $5 \mathrm{Kelvin}$ and a maximum of $8 \mathrm{~atm}$. Table III shows some of the operational statistics expected when modified for supercritical helium refrigeration.

Table II

A listing of some of the MFTF-B Cryogenic Plant operational characteristics

\begin{tabular}{|l|l|}
\hline Ist Stage Compressor & 1 to $2.5 \mathrm{~atm}$ \\
\hline 2nd Stage Compressor & 2.5 to 20 atm \\
\hline Max He flow in Compressor & $1000 \mathrm{~g} / \mathrm{s}$ \\
\hline Max He flow at $4.2 \mathrm{~K}$ & $540 \mathrm{~g} / \mathrm{s}$ \\
\hline Refrigeration Power & $11 \mathrm{~kW}$ \\
& $(8 \mathrm{~kW}+30 \mathrm{~g} / \mathrm{s}$ liquefaction $)$ \\
\hline
\end{tabular}

Table III

Operational characteristics of the Modified MFTF-B Cryogenic Plant for TPX supercritical Helium refrigeration.

\begin{tabular}{|l|l|}
\hline Ist Stage Compressor & 1 to $2.5 \mathrm{~atm}$ \\
\hline 2nd Stage Compressor & 2.5 to $8.0 \mathrm{~atm}$ \\
\hline 3rd Stage Compressor & 8 to $20 \mathrm{~atm}$ \\
\hline Max He flow in Compressor & $1000 \mathrm{~g} / \mathrm{s}$ \\
\hline Max He flow at $4.2 \mathrm{~K}$ & $540 \mathrm{~g} / \mathrm{s}$ \\
\hline Refrigeration Power & $10.3 \mathrm{~kW}$ \\
\hline
\end{tabular}

The two distinct differences in the two systems, as shown in the tables, are the 3rd stage of compression and the lower output of the Refrigeration Power. There are specific reasons for both changes.

The 3rd stage of compression is to minimize the heat of compression that the helium must see. Oil carry over caused by cracking due to the high compression ratios of the original MFTF-B system caused the MFTF-B system to shutdown due to oil precipitating out in the cold box purifier. The charcoal purifier is buried inside the cold box and not easy to access.

The lower output of the refrigeration system is due to the operational changes from an atmospheric liquefier to a supercritical refrigerator.

\section{A. Process}

The design utilizes the refrigeration power of the system through a several step cascade process. A simplified diagram of the process is shown in Fig. 1. In the following explanation refer to Fig. 1 for the referenced positions.

At position 1, the room temperature gas is compressed to $20 \mathrm{~atm}$ in 3 stages. The cold box uses counter flow heat exchangers and part of the $1000 \mathrm{~g} / \mathrm{s}$ helium stream to cool the incoming gas. The helium utilized for cooling is expanded through three turbines internal to the cold box (not shown in this simple schematic) with the final $540 \mathrm{~g} / \mathrm{s}$ of helium gas leaving the cold box at 4.7 Kelvin and 10 atm, position 2 .

The gas circuits are split into 3 parallel paths which have individual flow monitoring and a fixed ratio of flow in each circuit. The TF circuit is the dominant flow with the other two circuits ratioed from the TF. The individual control valves are not shown in this simple schematic.

The gas is further cooled by passing through a bath of liquid helium, position 3 . Upon exiting the dewar at $4.5 \mathrm{Kelvin}$ and $9 \mathrm{~atm}$ the helium begins its refrigeration duty. The heat loads of Table I must be absorbed. Many of these loads are pulsed and the dewar is used to buffer the heat load that the cold box will see. This will be explained in the Dewar Buffer Section.

After absorbing the magnet heat, the helium must cool the superconducting Bus, position 5. The temperature after position 5 is estimated at $6.0 \mathrm{~K}$. A return line for the helium through the bus duct provides cooling for a thermal shield around the bus, position 6 . The final heat load area is the TF Magnet case cooling at position 7. The temperature after position 7 was previously estimated above $7.1 \mathrm{~K}$ [2].

It would be impossible to JT from $7.1 \mathrm{~K}, 2.3 \mathrm{~atm}$ and obtain liquid helium. The gas stream exiting the case has picked up too much enthalpy. The Helium liquid in the dewar must 1st absorb much of the energy of this gas stream before a JT is encountered. Passing the $7.1 \mathrm{~K}$ helium through a heat exchanger, position 8 , and then a JT will allow the LHe to be formed in the dewar. This will, of course, boil off helium and raise the pressure in the dewar It is through this method that the dewar averages the heat load and buffers the peak loads.

During initial plasma generation, the total average heat load will be $6.2 \mathrm{~kW}$. For plasmas that generate Neutrons at $5 \mathrm{e}$ 16 per second, an average load of $8.1 \mathrm{~kW}$ will be absorbed. These loads are the averaged loads that will be seen by the helium system. Several of the loads are peaked at various times during the 1000 second plasma shot. These peak loads are much higher and are listed in Table IV.

\section{B. Dewar Buffer}

At the start of the pulse (1000 seconds long) the helium returning will JT from $5 \mathrm{~K}, 2.3 \mathrm{~atm}$ into the dewar at $4.4 \mathrm{~K}$ and $1.2 \mathrm{~atm}$. At the end of the 1000 second pulse the conditions will have absorbed part of the heat of the pulse and the dewar conditions will be $5 \mathrm{~K}$ at $1.6 \mathrm{~atm}$ This increase in pressure and temperature has absorbed most of the heat load. 
Additional heat will continue to be absorbed as the flow conditions continue to put energy into the dewar gas and liquid. It is estimated that 2300 seconds after plasma start that the entire heat of the pulse will have been removed from the structure and put into the dewar.

Table IV

Peak Loads on the magnets and structures with 5 e16 Neutrons per second plasma [1]

\begin{tabular}{|l|r|c|}
\hline AC & kJoules & per pulse \\
\hline PFI-7 & 227 & ${ }^{*}$ \\
\hline TF & 222 & ${ }^{*}$ \\
\hline Plasma Stabilization Coils & 1409 & ${ }^{* *}$ \\
\hline Nuciear & Watts & during pulse \\
\hline PFI-4 [3] & 9 & \\
\hline PF5 & 24 & $\dagger$ \\
\hline PF6 & 149 & $\dagger$ \\
\hline PF7 & 451 & $\dagger$ \\
\hline TF [4] & 2901 & $\dagger$ \\
\hline TF Case \& Structure [5] & 4440 & $\dagger$ \\
\hline
\end{tabular}

* $1 / 2$ of energy is in the plasma initiation (at approximately 5 seconds into the shot) and the second half of the energy is in the plasma ramp down at the end of burn (approximately the last 5 seconds).

**Actually $1400 \mathrm{~W}$ continuos when plasma stabilization coils are active. For 1000 second pulse $=1400 \mathrm{kJoules}$. No load once plasma is gone.

$\dagger$ These values are multiplied by $2 / 3$ since the reported reference evaluated the nuclear at 7.5 e16 Neutrons per second.

These loads must be totally buffered out so as to keep the operation of the cold box heat exchangers stable. If the helium flow increases on the return side (due to the boiling helium in the dewar as it absorbs the heat loads) the temperature on the heat exchanger will decrease causing an oscillation that will eventually shut down the helium cooling turbines in the cold box.

A constant pressure drop across the return line of the cold box the will keep a uniform mass flow through the cold box. This is of critical importance to minimizing flow and temperature oscillations in the cryogenic system. The primary and auxiliary dewar are used to accomplish a buffer system to handle these pulsed loads.

Position 9 shows an auxiliary dewar that is suspended in the ullage above the liquid. As the helium liquid and gas in the primary dewar rises in temperature, this dewar has a second JT valve that insures that the final conditions of the helium returning to the cold box, position 9, are a uniform $1.1 \mathrm{~atm}$ at 4.5 K. The auxiliary dewar fills with liquid helium which boils off at a nearly constant temperature due to the second volume isolation from the helium which is absorbing the pulsed loads of the magnets. If the heat load is small the primary dewar fills with liquid helium which will be used later to absorb the pulses and the auxiliary dewar JT valve functions in a bypass mode only and liquid would not be forming.
After giving up its refrigeration power and cooling the incoming stream the helium is returned to the suction side of the compressors.

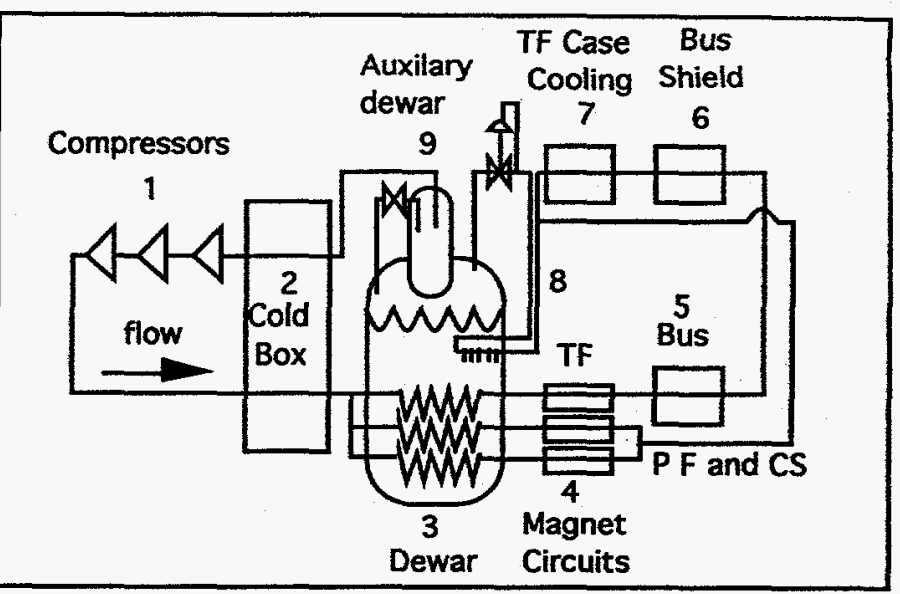

Fig. 1 Simplified diagram of the helium flow circuits of the entire system.

\section{OPTIONS}

The Initial system actually has several lines which feed the magnets. After the cold box the line is split in 3 sections. The largest of these flows nearly $400 \mathrm{~g} / \mathrm{s}$ through the TF Magnets, Bus, Shield and Case Cooling.

The other two lines feed the PF 1-4 (Central Solenoid) and PF 5-7 Coils. These coils require the remaining $140 \mathrm{~g} / \mathrm{s}$ of the cryogenic system. This totally accounts for the full flow available from the compressors.

The cascade system shown here (Magnets, Bus, Shield and Case Cooling) will likely be expanded to include the PF 6 and 7 coils due to the developing knowledge of the heat loads on these coils.

Due to the over commitment of helium flow capability, but not refrigeration power, the future upgrades will become important in the near future. If the project had not been canceled a redesign of the system would have occurred at this point since the present heat loads have now exceeded the capacity of the refrigerator to push the flows through the system. The refrigerator cooling capacity is still adequate but the flow characteristics through the system require the design to be readdressed.

\section{FUTURE UPGRADES}

The System will be designed so as to handle the full flow that would be required for the most extreme upgrade envisioned. The initial flows will be on the order of $540 \mathrm{~g} / \mathrm{s}$. The biggest upgrade envisioned will be on the order of $1000 \mathrm{~g} / \mathrm{s}$. All piping bringing the cryogen from the dewar to the cryostat and internal to the cryostat and will be sized to handle these flows. 
The cryogenic system itself will have a paralleling capability. Valves will be placed at strategic areas so that an additional refrigerator can be slaved to the system. This attachment will be made on the supply and return lines between position 2 and 3 in Fig. 1.

\section{SUMMARY}

The TPX Cryogenic System was designed to handle the highest full flows that were envisioned for all loads under all conditions. The system was designed around the MFTF-B Helium System that could be moved and used at PPPL for this experiment. The system was designed to be modular so that upgrades could be added incrementally so as to avoid high up front costs that may be minimized as the experiment progresses. This saved initial capitol costs and allowed for future options and upgrades to be implemented without affecting the flow system internal to the cryostat.

\section{ACKNOWLEDGMENTS}

Reference [6] is a previous paper which reported the initial design of this system previously. The design presented here is an update and refinement from this previous design.

The Authors would like to thank the two magnet vendors WEC and B\&W and their many personnel who gave constructive critiques on the cryogenic system. Their patience and insights were invaluable. Special thanks are also due to numerous CEBAF, MIT, ORNL, and PPPL personnel. This was a wide spread team that became close knit through Email, phones and travel.
This work performed under the auspices of the U.S. Department of Energy by Lawrence Livermore National Laboratory under contract number W-7405-ENG-48, and Princeton Plasma Physics Laboratory under contract number DE-AC02-76-CH03073.

\section{REFERENCES}

[1] B. Felker, "TPX Helium Heat Load," TPX Doc.\# 72950324-LLNL-BFelker-01, LLNL, March, 1995.

[2] R. L. Myatt, "Heat Flow from the TPX TF Coil Support Structure into the Winding Pack from 3-D Nuclear and Eddy Current Heat Loads, Revised Conduction Paths," TPX Doc.\# 13-940819-MIT-LMyatt-01, MIT, August, 1994.

[3] S. L. Liew, "Nuclear Heating Rates in Outer PF Coils with Shielded Pumping Ducts," TPX Doc.\# 94-941128-PPPLSLiew-01, PPPL, November, 1994.

[4] P. W. Wang, "TPX TF Steady-State Heat Removal of the New 1.25 Aspect Ratio DPC-U1 Conductor, Table 2," TPX Doc.\# 13-940601-MIT-PWang-01, MTT, June, 1994.

[5] P. W. Wang, "Impact on TPX TF Steady-State Heat Removal for 4.25" Inboard VV Envelope," TPX Doc. \# 13950314-MIT-PWang-01, MIT, March, 1995.

[6] D. Slack, "A Novel Scheme to Handle Highly Pulsed Loads with a Standard Helium Refrigerator," in Advances in Cryogenic Engineering, vol. 39, part B, pp. 1223-1229, July 1993. 